\title{
Social Media and Medical Applications in the Healthcare Context: Adoption by Medical Interns
}

\author{
Dalia Yahia M. El Kheir ${ }^{\mathrm{a}}$ Razan Z. AlShammari ${ }^{\text {b }}$ Raghdah A. Alamri ${ }^{\mathrm{b}}$ \\ Razan Abdulrahman AIShamsi ${ }^{b}$ \\ aDepartment of Family and Community Medicine, College of Medicine, Imam Abdulrahman Bin Faisal University, \\ Dammam, Saudi Arabia; ${ }^{b}$ College of Medicine, Imam Abdulrahman Bin Faisal University, Dammam, Saudi Arabia
}

\section{Keywords}

Social media - Medical applications - Telemedicine .

Healthcare delivery · Medical trainees · Ethics and privacy · Junior physicians

\begin{abstract}
Introduction: The widespread use of social media (SM) and medical applications (Apps) have improved the healthcare delivery and continued medical education in many forms, especially during COVID-19 pandemic. This study aimed to explore the perspective and practice of medical interns on the role of SM and medical Apps in delivering healthcare. Methods: A mixed-methods approach was used to collect data via both semi-structured interviews and an online selfadministered questionnaire. A total of 24 medical interns were interviewed ( 6 focus group discussions and 5 key informants' interviews), while 889 interns completed the online questionnaire. Interviews and their transcripts were analyzed and presented as themes and subthemes and frequencies were obtained from the self-administered questionnaire using SPSS v. 28. Results: Our studied interns believed that SM and medical Apps in healthcare delivery should be activated and deployed more since they will be using it increasingly in the future. They considered medical Apps such as
\end{abstract}

karger@karger.com www.karger.com/sjh

Karger!

GOPEN ACCESS
(C) 2022 The Author(s)

Published by S. Karger AG, Basel

This is an Open Access article licensed under the Creative Commons Attribution-NonCommercial-4.0 International License (CC BY-NC) (http://www.karger.com/Services/OpenAccessLicense), applicable to the online version of the article only. Usage and distribution for commercial purposes requires written permission.
UpToDate and Medscape as reliable and valid sources of medical information. Participants agreed that official Saudi Ministry of Health medical Apps, Mawid and Seha (Sehhaty), made radical change in healthcare delivery during COVID-19 pandemic. Interns' attitude toward using SM platforms in healthcare context changed during the pandemic as SM facilitated health promotion, sharing knowledge, and public health education. Nevertheless, interns discussed difficulties when health educating the public, and uncertainty regarding ethical and privacy aspects of communication with patients and colleagues via SM and medical Apps. Discussion/ Conclusion: Medical interns' use of SM and medical Apps for medical education and patient care is increasing. Overall, interns have a positive attitude toward the role SM and medical Apps can play in healthcare delivery; nevertheless, they were uncertain about related ethical and privacy issues.

(c) 2022 The Author(s)
Published by S. Karger AG, Basel

\section{Introduction}

During the last decade, the increasing use of social media (SM) and medical applications (Apps) has improved healthcare delivery and continued medical education in many forms including physician-patient communication 
and scientific online discussions [1]. In Saudi Arabia, the use of telemedicine started before the beginning of the COVID-19 pandemic. The Saudi Ministry of Health $(\mathrm{MOH})$ has developed several Apps to help improve the experience of delivering healthcare. One such example of digitalizing healthcare delivery is the "Mawid" App which enabled patients to make appointments for health services; "Mawid" was launched in 2017, and in 2018, the number of users exceeded 2.5 million [2].

Many factors were identified to affect the use of medical Apps and SM in delivering healthcare. These include personal factors like time constraints, knowledge factors like the lack of guidelines on how to use them and how to ensure the reliability of online information, factors related to the public like accessibility to internet and these technologies, ethical factors such as confidentiality and privacy concerns regarding using telemedicine tools, and even factors related to workplace acceptance and support [3-5].

COVID-19 pandemic has proven the necessity of adapting technology in providing healthcare and have also contributed in accelerating the integration of telemedicine use in the healthcare arena. Telemedicine technology and tools have helped in many ways, starting from the education of the public and all the way to managing patients remotely $[6,7]$. Nowadays, coronavirus spread prevention is the focus of response efforts by worldwide healthcare organizations and adopting a perfect telemedicine system is an ideal way to avoid unnecessary patient exposures and maintaining the delivery of best care [8].

Thus, it is very clear that the utilization of telemedicine services is changing, allowing us to continue to provide high-quality healthcare, and it is expected to change more with more development of technology [9]. Therefore, in this research, we aimed to study the perspective and practice of future physicians, medical interns, on the use of SM and medical Apps in delivering healthcare. We expect the results of this research would be utilized to implement further measures, such as targeted training, to improve their experience with these technologies and ensure their patients receive an optimal quality of care.

\section{Materials and Methods}

A mixed-methods design (triangulation design and convergence model) was used and both quantitative and qualitative data were collected during the same time period, giving equal weight to both. Following the triangulation convergence model, the resulting quantitative and qualitative data were analyzed separately then the different results were interpreted together to validate and clarify the different aspects discussed in this study.

Social Media and Medical Applications in Healthcare: Interns
Data collection was conducted between June 2020 and September 2020 via both: semi-structured interviews-focus group discussions (FGDs) and key informant (KI) interviewees; and a self-administered online questionnaire distributed via SM targeting specific medical interns' groups in the 5 main regions of Saudi Arabia. Our study targeted medical interns who were at the end of their 1-year internship training period.

Six FGDs (A-F) and $5 \mathrm{KI}$ interviews (K1-K5) were conducted, with a total of 24 participants. The inclusion criteria for KIs were as follows: medical interns who were part of a student's council, students' clubs, or any other similar party. A purposeful sampling method was used to recruit FGD participants in order to ensure all of the 5 main regions (eastern, western, central, northern, and southern regions) of Saudi Arabia were represented.

Possible participants were contacted mainly through Twitter direct messaging $(n=15)$ and recruited via face-to-face contact $(n$ $=9$ ). The study was explained to the participants and they were invited to participate in the qualitative FGD or KI interview. Interns' recruitment was stopped when data saturation was observed to be reached.

The interviews were performed via the Zoom platform, version 5.2.1. Interviews were audio-recorded, after obtaining the participants' informed consent, and then transcribed verbatim. The average time of each FGD was 1 hour and 22 min for KI interviews.

For the online survey, cross-sectional quantitative part of the study, the inclusion criteria were as follows: medical interns, males and females, working/training in any of the 5 main regions (eastern, western, central, northern, and southern regions) of Saudi Arabia, and who had completed their full internship training year, 2019-2021, by July 2020. The minimum sample size was calculated as 384 interns using the EpiInfoTM Software, by which the confidence interval was set at $95 \%, p$ value at 0.05 and a margin of error at $5 \%$. To ensure adequate sampling of the medical interns working in the 5 main regions of KSA, the final sample collected was 889 medical interns.

Both of the interviews and the online self-administered survey addressed 12 questions regarding the following main aspects about the interns' use of SM and medical Apps in delivering healthcare: the participants' use of SM and medical Apps, their general perceptions on the suitability of SM and medical Apps for use in healthcare delivery at present and in the future, and confidentiality and privacy aspects related to the use of these tools in the healthcare context, in addition to the effect of COVID-19 on their use of SM and medical Apps.

The interviews were transcribed, coded, and then analyzed and organized into themes and subthemes. Two researchers (R.Z.A. and R.A.S.) coded the data manually and these were reviewed by a third researcher (D.Y.M.E.). In addition, the online survey, crosssectional quantitative data were organized and analyzed as tables, frequencies, and percentages, using the standard computer program IBM Statistical Package for the Social Sciences (SPSS) Statistics for Mac, version 28.0 program.

Ethical approval for this study was obtained from the Institutional Review Board of Imam Abdulrahman Bin Faisal University, Saudi Arabia. Written informed consent was obtained from all study participants prior to data collection, and they were reassured that all data will be kept confidential and they have the right to withdraw from the study at any time.

Saudi J Health Syst Res 2022;2:32-41 
Table 1. Characteristics of study participants

\begin{tabular}{lll}
\hline Participants' characteristics & $\begin{array}{l}\text { Qualitative interviews, } \\
\text { frequency, } n(\%)\end{array}$ & $\begin{array}{l}\text { Quantitative cross-sectional } \\
\text { survey, frequency, } n(\%)\end{array}$ \\
\hline $\begin{array}{l}\text { Sex } \\
\text { Male }\end{array}$ & $9(37.5)$ & $456(51.3)$ \\
$\quad$ Female & $15(62.5)$ & $433(48.7)$ \\
Nationality & $22(91.7)$ & $865(97.3)$ \\
$\quad$ Saudi & $2(8.3)$ & $24(2.7)$ \\
Non-Saudi & $218(24.5)$ \\
Residential areas & $5(20.8)$ & $240(27.0)$ \\
$\quad$ Central province & $7(29.1)$ & $133(15.0)$ \\
Western province & $7(29.1)$ & $163(18.3)$ \\
Eastern province & $4(16.6)$ & $135(15.2)$ \\
Southern province & $1(4.1)$ & $n=889$ \\
Northern province & $n=24$ & \\
\hline Total & & \\
\hline
\end{tabular}

\section{Results}

The team invited 24 medical interns to participate in the semi-structured interviews and stopped once the data saturation was evident. In addition, a total of 889 medical interns completed the self-administered online questionnaire. The mean age of the participants was 25 years (age range: 23-30 years). Further participants' characteristics are summarized in Table 1.

\section{Present and Future Technology}

Several of our interviewees were enthusiastic about the role of technology, SM and medical Apps, in healthcare delivery. "As what we see nowadays during the pandemic. Technology helped the health care a lot. We have to use it. So, it's a good idea to prepare for it early" K1.

Yet, other interns think that there is need to activate and deploy technology in Saudi Arabia more. "I think technology should be activated even more than now" K2. This difference in opinion was reflected by our surveyed interns of whom $(38.1 \%, n=339)$ were unsure whether, in general, SM and medical Apps can be used to facilitate the process of healthcare delivery. Nevertheless, our interviewees believed that technology use in healthcare delivery will increase in the future. " $\mathrm{Al}$ ready we begin with corona and we saw its role and as long as it's succeeding now it will be the future and in the near future" B2. "Before corona, there were main PHCs (primary healthcare centers) applying the Mawid App (an official App provided by the Saudi Ministry of Health for scheduling patient appointments) system but not all as strictly as now. Corona helps us to apply our knowledge" F3.

\section{Medical Apps}

Our surveyed interns were asked about the medical Apps that they are using and the reason for use. Table 2 shows that UpToDate was chosen as the top App favored by $63.6 \%(n=565)$ of the interns followed by Medscape $(59.3 \%, n=527)$. Table 3 presents the themes and subthemes that emerged from further discussions with our interviewed interns, with supporting quotes for illustration categorized as clinical services, own formal or informal medical education, and use in the public domain for sending public health messages or sharing interesting health information.

\section{Willingness to Pay for Medical Apps}

Interns were asked about their opinion, if they did not have access to these Apps via their workplace, would they subscribe to them personally or not and the reason. Our data show that interns are willing to pay for access if it will benefit them; Table 3 presents their quotes for illustration. These results are similar to our survey data in which $72.8 \%(n=647)$ stated that the cost of heath Apps was not a barrier to use them.

\section{Official Medical Apps Provided (Free of Charge) by} the Saudi $\mathrm{MOH}$

Our interns were asked about the Saudi MOH-sponsored medical Apps they have utilized the most during the COVID-19 pandemic. As illustrated in Table 2, both Mawid and Seha (or Sehhaty) Apps (Seha App is an official App sponsored by the Saudi $\mathrm{MOH}$ and provides a wide range of services including online doctor consultations) were utilized by our interns $(24.1 \%, n=214$, and $24.3 \%, n=216$, respectively). In addition, almost all in- 
Table 2. Quantitative, cross-sectional study results

\begin{tabular}{|c|c|}
\hline Application & Frequency, $n(\%)$ \\
\hline \multicolumn{2}{|c|}{$\begin{array}{l}\text { Which of the following medical Apps have you utilized the most during } \\
\text { COVID-19 pandemic?* }\end{array}$} \\
\hline \multicolumn{2}{|c|}{ Seha App ${ }^{1}$ (Saudi Ministry of Health) } \\
\hline Selected & $216(24.3)$ \\
\hline Not selected & $673(75.7)$ \\
\hline \multicolumn{2}{|c|}{ Arshidni App ${ }^{2}$ (Saudi Health Council) } \\
\hline Selected & $95(10.7)$ \\
\hline Not selected & $794(89.3)$ \\
\hline \multicolumn{2}{|c|}{ Awquifha App ${ }^{3}$ (Saudi Health Council) } \\
\hline Selected & $58(6.5)$ \\
\hline Not selected & $831(93.5)$ \\
\hline \multicolumn{2}{|c|}{ Mawid $\mathrm{App}^{4}$ (Saudi Ministry of Health) } \\
\hline Selected & $214(24.1)$ \\
\hline Not selected & $675(75.9)$ \\
\hline \multicolumn{2}{|c|}{ Asafny $\operatorname{App}^{5}$ (Saudi Red Crescent Authority) } \\
\hline Selected & $146(16.4)$ \\
\hline Not selected & $743(83.6)$ \\
\hline \multicolumn{2}{|c|}{ Which of the following medical Apps have you utilized for patient care?* } \\
\hline \\
\hline Selected & $293(33.0)$ \\
\hline Not selected & $596(67.0)$ \\
\hline \multicolumn{2}{|l|}{ UpToDate } \\
\hline Selected & $565(63.6)$ \\
\hline Not selected & $324(36.4)$ \\
\hline \multicolumn{2}{|l|}{ MDCalc } \\
\hline Selected & $172(19.3)$ \\
\hline Not selected & $717(80.7)$ \\
\hline \multicolumn{2}{|l|}{ Medscape } \\
\hline Selected & $527(59.3)$ \\
\hline Not selected & $362(40.7)$ \\
\hline \multicolumn{2}{|c|}{$\begin{array}{l}\text { Frequently used medical apps in healthcare delivery. }{ }^{1} \text { Seha: App } \\
\text { provides a wide range of services including home-health and } \\
\text { preventative care, also online doctor consultation by text, audio, or } \\
\text { video. }{ }^{2} \text { Arshidni: App aims to enhance the health awareness of the } \\
\text { Saudi community about cancer, and to disseminate health care } \\
\text { informationand health services related to cancer patients. }{ }^{3} \text { Awquifha: } \\
\text { App aims to raise the level of public awareness about the dangers of } \\
\text { smoking, complications, and harmful secondary effects. }{ }^{4} \text { Mawid: App } \\
\text { that enables patients to make appointments for health services. } \\
{ }^{5} \text { Asafny: App aims to provide emergency medical services in all } \\
\text { administrative regions of the kingdom of Saudi Arabia faster as the } \\
\text { access to patient's information and location with the app is easier. } \\
\text { *Participants were allowed to select multiple responses in this } \\
\text { question. Selected = yes; not selected = no. }\end{array}$} \\
\hline
\end{tabular}

terviewed interns who used the MOH Apps Seha and Mawid had a very satisfying experience and they believed that these Apps were making a good impact in facilitating healthcare delivery in Saudi Arabia. "The latest applications for $\mathrm{MOH}$ are making radical change in the healthcare delivery" K1. "Easy and simple to use" F1. "It saves us a lot, even with the patient data" F2. Nevertheless, not all the interviewed interns used these Apps; however, some of them heard about their usefulness. "I heard about them that they are useful, but I have not used them" B2.

\section{Frequently Used SM Platforms for Healthcare}

Our survey identified Twitter and WhatsApp as those SM platforms that interns frequently used for medical education purposes $(72.7 \%, n=216$, of Twitter users and $61.8 \%, n=264$, of WhatsApp users). The semi-structured interviews further explored the interns' experience with these platforms; Table 3 presents the themes and subthemes that emerged from the discussions, with supporting quotes for illustration categorized as clinical services, own formal or informal medical education, and use in the public domain for sending public health messages or sharing interesting health information.

\section{COVID-19 Affecting the Attitude toward Using SM and Medical Apps}

Interns were asked whether their attitude toward using SM and medical Apps changed, either positively or negatively, due to COVID-19 pandemic. Several interns claimed that COVID-19 changed their attitude. "... a lot of things change either for personal use or education. Many courses now are run online. Many medical consultations are online" K1. "The pandemic is something new. All what's there is new research. We can't find them in the books. So, SM and medical applications contributed to form this knowledge" K2. "Yes, I read UpToDate quite more. In SM there was more health promotion in twitter to limit the spread of wrong information, so this is a very good action" D2. On the other hand, some interns' use of SM and medical Apps did not change during the pandemic. "... it didn't change because we used SM before corona" F2.

Survey results revealed that $80.5 \%(n=716)$ of the sampled interns agree that SM and medical Apps facilitated the process of healthcare delivery during COVID-19 pandemic (Table 4). This opinion was also reflected by our interviewees. "...during this experience (COVID-19 pandemic) the (Saudi)MOH was highly updated in twitter. We follow the cases, health education and when the $\mathrm{MOH}$ sent updated instruction on how to manage different diseases at home" F2. "At the beginning of this pandemic we did multiple filed campaigns to educate the public, however, when the number of the (COVID-19) cases increased we had to switch to the online education via SM. Twitter helped a lot, it got a great reaction. Other than this, we were able to advertise for a meeting talking about COVID-19 for the public. Also, we did a competition for health promo- 
Table 3. Qualitative study results

\begin{tabular}{|c|c|}
\hline Theme & Supporting quotes \\
\hline \multicolumn{2}{|c|}{$\begin{array}{l}\text { Which SM platform and medical Apps do you frequently use and why? } \\
\text { Used in clinical services }\end{array}$} \\
\hline BMJ & $\begin{array}{l}\text { "I found it to be easier, has all the specialties, and you can download the } \\
\text { content on your phone... what I mean is that you can find the information } \\
\text { quickly and it is more organized." C1 }\end{array}$ \\
\hline MDCalc & $\begin{array}{l}\text { "...to calculate medical numbers... use it if I want to remember something } \\
\text { or for calculations quickly." K4 }\end{array}$ \\
\hline Twitter & $\begin{array}{l}\text { "I am using it more for my medical education when I follow medical journals, } \\
\text { societies and health promotion." D3 } \\
\text { "... because there are official and important accounts MOH, universities, } \\
\text { Medscape, doctors, other official accounts..." E1 "... because of the } \\
\text { summaries the doctors post." A3 }\end{array}$ \\
\hline
\end{tabular}

Used in public domain for sending public health messages or sharing interesting health information

Twitter

“...it includes various news... I feel like it's the only platform that group everything from the health perspective or other." F3

"...to know the news even before it reaches the other media channels." K1

"... because there are official and important accounts $\mathrm{MOH}$, universities, Medscape, doctors, other official accounts..." E1

WhatsApp

"...WhatsApp is better than twitter in the fact that everyone has WhatsApp even the elderly unlike twitter." A1

"...most people have WhatsApp unlike other apps." K5

If an intern did not have access to (the mentioned) medical Apps via their workplace, would he/she pay to subscribe to them personally? And why? Willingness to pay for medical apps

"As long as it's there to facilitate us to get the knowledge and provide the best care yes, I will especially if it's with my specialty." F3 "depends on the financial status." A2

"I don't mind paying for subscription, but I might try to talk to the institution to provide free access." E1

Main themes, subthemes, and supporting quotes relating to frequently used medical Apps and SM platforms.

tion. All in twitter with no face-to-face interaction" K1. "In $S M$ we can provide general information for the public about different disease, we can also use SM for advice regarding specific issues, like what is happening nowadays with COVID-19 where the information is simplified so everyone could understand it" A2. "Before corona (CO-
VID-19 pandemic) I wasn't convince with the use of it (SM and medical apps) in healthcare delivery. But after we used it I can say it made a difference. It facilitates the health delivery for the medical staff and for the patient. Nowadays it has become a necessity, rather than a preference, to incorporate them (SM and medical apps) in healthcare de- 
Table 4. Quantitative, cross-sectional study results

\begin{tabular}{|c|c|}
\hline Question & $\begin{array}{l}\text { Frequency, } \\
n(\%)\end{array}$ \\
\hline \multicolumn{2}{|c|}{ Do you think SM and medical apps have facilitated the process of healthcare delivery during COVID-19 pandemic? } \\
\hline Yes & $716(80.5)$ \\
\hline No & $71(8.0)$ \\
\hline I do not know & $102(11.5)$ \\
\hline Total & $889(100.0)$ \\
\hline \multicolumn{2}{|c|}{$\begin{array}{l}\text { It is possible to maintain clear boundaries between personal and professional relationships while using SM to } \\
\text { communicate with patients }\end{array}$} \\
\hline Strongly agree & $214(24.1)$ \\
\hline Agree & $227(25.5)$ \\
\hline Not sure & $303(34.1)$ \\
\hline Disagree & $111(12.5)$ \\
\hline Strongly disagree & $34(3.8)$ \\
\hline Total & $889(100.0)$ \\
\hline \multicolumn{2}{|c|}{ It is ethical to share patients' pictures on SM if we received their consent } \\
\hline Strongly agree & $197(22.2)$ \\
\hline Agree & $213(24.0)$ \\
\hline Not sure & $266(29.9)$ \\
\hline Disagree & $117(13.2)$ \\
\hline Strongly disagree & $96(10.8)$ \\
\hline Total & $889(100.0)$ \\
\hline
\end{tabular}

livery" K3. "One time I wrote (in SM) about the polycystic ovary syndrome for the general (public) knowledge, and during the pandemic I wrote a simple thing on how to sterilize and prevent COVID-19 infection. A little bit of education" F1.

\section{SM for Public Health Education}

Among the surveyed interns, 33.7\% $(n=300)$ used SM for public health education. Twitter was the SM platform chosen by our interviewees who had tried conducting public health education through SM. Nevertheless, although they have done it, interns felt they are not authorized to engage in these public health education activities with the public via SM. "I used twitter to advertise to a health campaign... however, I don't think I am in a position that allow me to share health information" D1.

Different interns had different experiences in using SM for public health education purposes. They faced some challenges, and the target population was one of these challenges. "... the difficulties we faced were how to reach the public and the few interactions (responses in Twitter) in the beginning it was like if we were talking to ourselves" A3.

In twitter, there are followers from different cultures and background, so the ability to raise their awareness about some topics was challenging. "... one of the difficul-

Social Media and Medical Applications in Healthcare: Interns ties we faced is when some people attacked/opposed our account and started posting the false information" C3.

On the other hand, some interns have not tried public health education via SM. "My account is private, I never used it for patient education or patient care" D3. Still, others were outright opposed to the idea. "I don't think I will use it for health education because I feel twitter is a huge platform and any word that you post there could have a positive or negative impact. But if there is a specific website for health education and promotion it will be better and more professional. Recently, I read that $60 \%$ of people take doctor opinions on twitter and in Instagram as well, as a result we have to be more careful and more responsible of what we are saying on SM" D4.

\section{Sharing SM Accounts with Patients}

Interns were asked if their patients asked for their personal accounts, would they give it immediately? Their opinions were divided between those who disagree if it is a personal account, "... I don't think I will give it's a personal account" D1, and those who agree to do so if the contents would benefit the patients, "Sure I'll give them and it's my pleasure, if they want to ask me something about their condition or when they want some instruction after surgery for example, they are more than welcome" C1. 
"It's not a problem to give them my personal account but I will clearly explain that it's a private account and it doesn't contain any medical content and I will not respond to any medical questions or any consultation" C2.

Yet other interns were concerned that the doctor-patient relationship could be affected by sharing doctors' personal accounts. "When the patient read my info could agree with it could not and this have its own consequences. It should be an official account. I always said that if the doctor has public account on twitter, I think he shouldn't post his own views regarding the community or trends. He may lose his trustiness. People should understand the difference, but unfortunately, they are not" F1. Surveyed interns showed similar patterns of opinion, with $(34.1 \%$, $n=303$ ) not sure whether it is possible to maintain clear boundaries between personal and professional relationships while using SM to communicate with patients (Table 4).

\section{Confidentiality and Privacy in SM and Medical Apps}

When they were asked about whether it is ethical to share patients' pictures on SM if we received their consent, $29.9 \%(n=266)$ of our surveyed interns were not sure (Table 4). This is similar to the response of our interviewees. Some interns stated that there is no problem in sharing patient medical data if there is no identifying information. They explained that sharing of these cases will help the community and spread awareness. "In SM the level of privacy and confidentiality is high and I approve telling stories without saying names and the hospital name in order to educate the public, and I think we need to share more stories to raise awareness" E3. "SM usually has advice so I don't think there is a problem with that, and in medical applications I think the level of confidentiality is high because only those who are in the medical field view it" A2. However, other interns do not support this view, explaining: “... even when the patient agrees, I don't think it's okay to publish. If it is very interesting and you want to share I think the best thing is to go with the traditional methods (such as) case reports or you can share in 'Figure 1'...” D1.

\section{Discussion/Conclusion}

Concerning the future, several of our interviewed interns were enthusiastic about the role of technology and think it helped a lot in delivering care especially in COVD19 pandemic. Furthermore, the majority agreed that they will be using it more in the future. This is consistent with a narrative review that included 42 articles which con- cluded that, in the future, technology should be fully incorporated into the healthcare landscape not only for regular services but also for future pandemics [9].

In our study, UpToDate was the top used app, followed by Medscape, BMJ, and MdCalc among surveyed interns. They described UpToDate and Medscape as valid, reliable, easy to use, and helpful in reaching a diagnosis. The ability of UpToDate to synthesis relevant information, being updated regularly, and having wide collection of subspecialties are common features that made it popular [10]. In addition, it was one of the most commonly used Apps mentioned in different studies including one national study conducted in Saudi Arabia which reported that the medical Apps used by physicians included Medscape, UpToDate, and BMJ. Physicians claim that these Apps help in improving clinical decision-making, saving more time, and allowing faster access to clinical practice guidelines [11]. Yet another study conducted in the UK found that students used medical Apps for diagnosis, management, and drug reference, with physicians favoring clinical score and calculator apps [12].

Regarding willingness to pay for medical Apps, our data suggested that most of the interns are willing to pay to have access to medical Apps if it will facilitate in providing the best care or getting the best knowledge. Others were not sure saying it depend on their financial status. In 2014, a study estimated that the average for a student to pay for profound Apps was 14.35 EUR [13]. However, other physicians felt that they would not subscribe personally to UpToDate even if the hospital ceased its institutional subscription [10].

Another area of interest was the Saudi MOH official Apps. In Saudi Arabia, the aim is to expand telemedicine services through Seha (or Sehhaty) App. This App provides visual online medical consultations by allowing all citizens anywhere to have virtual, face-to-face, medical consultations with their doctors across the Kingdom of Saudi Arabia [14]. Mawid and Seha were the most common Apps mentioned by our interns as they agreed on the usefulness of these Apps even though some of them did not use them. This result is similar to that of a study conducted in Saudi Arabia to evaluate the effectiveness of the Seha App in improving healthcare delivery. The study showed that out of 528 of the general Saudi public, $47.1 \%$ $(n=249)$ are using Seha App and these users reported a better health experience, improved access to healthcare services, and satisfaction with the healthcare services [15]. On the other hand, 52\% $(n=410)$ have never used the Seha App before [16].
38

Saudi J Health Syst Res 2022;2:32-41 DOI: $10.1159 / 000521635$
El Kheir/AlShammari/Alamri/AlShamsi 
Our study showed that WhatsApp and Twitter Apps were the two main SM platforms most of the surveyed interns were interested in and used frequently for medical education purposes. For Twitter, they agreed that it is a platform that contains everything which was helpful in getting news and information. For WhatsApp, our interviewees explained that most of the people use it even the elderly. These findings challenge some of the results of available international literature which reported Facebook and YouTube as the most used SM platforms by interns $[17,18]$. Also, other local studies found that YouTube was the most used SM platform, followed by Twitter $[19,20]$. However, an Iranian study showed a similar result and found Twitter to be the most used application among physicians. It meets physicians' needs in terms of keeping them up-to-date primarily because of its popularity among the medical community, and therefore, the attendance of a professional clinical audience. They believed that using SM is helping to stay connected with colleagues and networking with wider community $[4,21$, 22].

During the current COVID-19 outbreak, the attitude of interns toward using SM and medical Apps has changed. More than 3 quarters of our surveyed interns agreed that SM and medical Apps facilitated the process of healthcare delivery during the pandemic. For the interviewed interns, most of the patients' consultations and educational courses were held online which were some of the main purposes for increasing the use of medical Apps, as well as learning more about the pandemic from (official) SM accounts. Other studies found that gaining information about COVID-19 among physicians and promoting behaviors to prevent COVID-19 among the public were also common motives for using SM and medical Apps [23-25]. In fact, research has shown that the usage of SM tends to increase in natural disasters and crises which is consistent with our data [26].

For public health education and promotion, SM tools can be broad and varied [27]. SM can provide an important opportunity for physicians to share evidence-based information to correct any inaccurate medical information on the internet [28]. It can also benefit the patients through education, receiving support, obtaining information, goal setting, and tracking personal progress $[21,29]$. In our study, part of our participants used SM for public health education and described differing opinions and experiences. Some interns are willing to educate the public, and others think they are not authorized to perform this task. Interns

Social Media and Medical Applications in Healthcare: Interns also discussed some difficulties they had faced in reaching the targeted population or in correcting false information. A study in Saudi Arabia found that almost half of the physicians believed that a patient will not trust the advice of a doctor if he receives that medical information via a website [22].

Regarding sharing information on SM platforms, many researchers extol SM as a promising tool to allow medical professionals to reach a broad audience including physicians, trainees, and patients in addition to involving patients more in their own care [30]. Our data revealed that some interns were willing to share their personal SM account with patients, while others were not sure that it was possible to maintain clear boundaries between personal and professional relationships with patients on SM. A study found that more than half of the questioned physicians did not feel comfortable interacting online with their patients who had accessed personal information about them online, prior to the consultation [31]. In India, physicians were interviewed and said that they have never initiated online contact with patients on any SM forum and they would only accept friend requests from patients who they considered safe to have contact with [32].

Sharing personal health information on SM can be highly rewarding, but it also contains a potential risk [33]. Our interns believed that sharing cases with no identifying information was not an issue, especially if they had that patient's consent. However, a recent study conducted in Saudi Arabia revealed that physicians considered safety incidents which occurred in hospitals should not be shared through SM as it may affect the privacy of the hospital and the patients [34]. Furthermore, the available scientific literature maintains that physicians must carefully uphold professional relationships and confidentiality in online settings ensure patient data security and privacy and pay utmost attention when transmitting a patient's data to others while requesting a second opinion as this communication is strongly characterized by medical confidentiality, trust, and privacy [35-37]. From patients' perspective, a study conducted among teenage patients found that most adolescent patients do not disclose their personal health information on SM, which is a place where they stay up-to-date about their social life and thus do not see it as a place to discuss their health issues [38].

Our study has several strengths. First, it is a national sample, covering the 5 main regions in Saudi Arabia (central, eastern, western, northern, and southern regions) and as such caters for the experience and opinions of 
medical interns in most of Saudi Arabia. Second, our interns were recruited at the end of their internship training which ensures their opinions to be reliable and truly represent a typical medical intern's perspective. In addition, our data were collected a few months after the beginning of the current COVID-19 pandemic which also ensured the relative familiarity of our interns with the discussed aspects of SM and medical Apps' use in the healthcare context. However, the findings of this study have to be considered in light of some limitations. Our targeted participants are medical interns who generally might be considered to have limited online communication with patients. Thus, generalization of our results to more senior medical trainees and physicians who have different experiences of online interactions with patients should be done with caution. Future research addressing the experience of other healthcare provider categories and differing contexts is needed.

In conclusion, the use of SM and medical Apps among medical interns is increasing and they consider medical Apps as a valid and reliable source of scientific medical information. The MOH Apps, Mawid and Seha (Sehhaty), were used by some interns especially during COVID-19 pandemic. Different purposes for using SM and medical Apps, including public health education, were discussed by our participants as well as some related ethical and privacy issues, such as online sharing of patients' information by physicians and sharing of physicians' personal SM accounts with patients. These discussions revealed quite differing opinions among medical interns, ranging from those who support to those who oppose with a number of unsure participants in between. Considering the rapid development of the internet and emerging technologies and the expanding use of SM and medical Apps in providing health and facilitating the process of healthcare delivery nowadays, early training of medical personnel on the proper use of these technologies in the healthcare context is vital.

\section{Acknowledgments}

We wish to express our special appreciation and thanks to all our study participants, the medical interns, for their willingness to join this research and share their perspective on the study topic.

\section{Statement of Ethics}

The study was held in accordance with the World Medical Association Declaration of Helsinki 1975 (revised in 2000). Ethical approval for this study was obtained from the Institutional Review Board (IRB) of Imam Abdulrahman Bin Faisal University in Saudi Arabia, vide letter No. IRB-UGS-2019-01-205. Written informed consent was obtained from all study participants prior to data collection, and they were reassured that all data will be kept confidential and they have the right to withdraw from the study at any time.

\section{Conflict of Interest Statement}

The authors have no conflicts of interest to declare.

\section{Funding Sources}

The authors did not receive any funding.

\section{Author Contributions}

D.Y.M.E. conceived the concept and design choice for the study and has a role in implementing the study, data collection, analysis, and interpretation of data and contributed substantially to the writing of this article, read, edited, and approved its final version and is the corresponding author. R.Z.A. and R.A.S. have similar roles in data collection, analysis and interpretation of data, and contributed substantially to the writing of this article, read, edited, and approved its final version. R.A.A. has a role in data analysis and interpretation, and contributed substantially to the writing of this article, read, edited, and approved its final version. All authors have reviewed and approved the final draft and are responsible for the content and similarity index of the manuscript.

\section{Data Availability Statement}

The datasets used for the current study are available from the corresponding author on reasonable request.

\section{References}

1 Zimba O, Radchenko O, Strilchuk L. Social media for research, education and practice in rheumatology. Rheumatol Int. 2020;40:18390.

2 Vision progress/Saudi vision 2030 [Internet]. Vision2030.gov.sa. [cited 2020 Aug 18]. Available from: https://vision2030.gov.sa/en/ vision-progress.
3 Campbell L, Evans Y, Pumper M, Moreno MA. Social media use by physicians: a qualitative study of the new frontier of medicine. BMC Med Inform Decis Mak. 2016;16(1): 91.

4 Panahi S, Watson J, Partridge H. Social media and physicians: exploring the benefits and challenges. Health Informatics J. 2014;22(2): 99-112.
5 Kessel K, Vogel M, Schmidt-Graf F, Combs S. Mobile applications in oncology: a survey on health care professionals' attitude toward telemedicine, mHealth, and oncological apps. J Med Internet Res. 2016;18(11):e312.

6 Hollander JE, Carr BG. Virtually perfect? Telemedicine for Covid-19. N Engl J Med. 2020;382(18):1679-81. 
7 Al-Sofiani ME, Alyusuf EY, Alharthi S, Alguwaihes AM, Al-Khalifah R, Alfadda A. Rapid implementation of a diabetes telemedicine clinic during the Coronavirus disease 2019 outbreak: our protocol, experience, and satisfaction reports in Saudi Arabia. J Diabetes Sci Technol. 2021;15(2):329-38.

8 Lovett Rockwell KS, Gilroy A. Incorporating telemedicine as part of COVID-19 outbreak response systems. Am J Manag Care. 2020; 26(4):147-8.

9 Kichloo A, Albosta M, Dettloff K, Wani F, ElAmir Z, Singh J, et al. Telemedicine, the current COVID-19 pandemic and the future: a narrative review and perspectives moving forward in the USA. Fam Med Community Health. 2020;8(3):e000530.

10 Phua J, Lim TK. How residents and interns utilise and perceive the personal digital assistant and UpToDate. BMC Med Educ. 2008; 8(39):39.

11 Al-Ghamdi S. Popularity and impact of using smart devices in medicine: experiences in Saudi Arabia. BMC Public Health. 2018; 18(1):531.

12 Payne KB, Wharrad H, Watts K. Smartphone and medical related App use among medical students and junior doctors in the United Kingdom (UK): a regional survey. BMC Med Inform Decis Mak. 2012;12:121.

13 Sandholzer M, Rurik I, Deutsch T, Frese T. Medical students' expectations towards an implementation of a family medicine textbook as a comprehensive app in Germany. J Med Syst. 2014;38(10):125.

$14 \mathrm{MOH}$ News- $\mathrm{MoH}$ : all the kingdom will be covered by telemedicine in two months. Moh. gov.sa. 2020 [cited 2020 Aug 13]. Available from: https://www.moh.gov.sa/en/Ministry/ MediaCenter/News/Pages/news-2018-0306-006.aspx.

15 Alharbi A, Alzuwaed J, Qasem H. Evaluation of e-health (Seha) application: a cross-sectional study in Saudi Arabia. BMC Med Inform Decis Mak. 2021;21(1):103.

16 Alshammari F, Hassan S. Perceptions, preferences, and experiences of telemedicine among users of information and communication technology in Saudi Arabia. J Health Informatics Dev Ctries. 2019;13(1).
17 Wang AT, Sandhu NP, Wittich CM, Mandrekar JN, Beckman TJ. Using social media to improve continuing medical education: a survey of course participants. Mayo Clin Proc. 2012;87(12):1162-70.

18 Antheunis ML, Tates K, Nieboer TE. Patients' and health professionals' use of social media in health care: motives, barriers and expectations. Patient Educ Couns. 2013;92(3):42631.

19 Alanzi T, Al-Habib DK. The use of social media by healthcare quality personnel in Saudi Arabia. J Environ Public Health. 2020;2020: 1417478.

20 Alsuraihi AK, Almaqati AS, Abughanim SA, Jastaniah NA. Use of social media in education among medical students in Saudi Arabia. Korean J Med Educ. 2016;28(4):343-54.

21 Househ M. The use of social media in healthcare: organizational, clinical, and patient perspectives. Stud Health Technol Inform. 2013; 183:244-8.

22 Alanzi T, Al-Yami S. Physicians' attitude towards the use of social media for professional purposes in Saudi Arabia. Int J Telemed Appl. 2019;2019:6323962.

23 Subedi P, Thapa B, Pandey A. Use of social media among intern doctors in regards to $\mathrm{Co}$ vid-19. Europasian J Med Sci.. 2020;2(1):5664.

24 Mat Dawi N, Namazi H, Hwang H, Ismail S, Maresova P, Krejcar O. Attitude toward protective behavior engagement during $\mathrm{CO}$ VID-19 pandemic in Malaysia: the role of Egovernment and social media. Public Health Front. 2021;9:60971.

25 Li X, Liu Q. Social media use, eHealth literacy, disease knowledge, and preventive behaviors in the COVID-19 pandemic: cross-sectional study on Chinese Netizens. J Med Internet Res. 2020;22(10):e19684.

26 Niles MT, Emery BF, Reagan AJ, Dodds PS, Danforth CM. Social media usage patterns during natural hazards. PLoS One. 2019;14 e0210484.
27 Jawad M, Abass J, Hariri A, Akl EA. Social media use for public health campaigning in a low resource setting: the case of waterpipe tobacco smoking. Biomed Res Int. 2015;2015: 562586.

28 Dizon D, Graham D, Thompson M, Johnson LJ, Johnston C, Fisch MJ, et al. Practical guidance: the use of social media in oncology practice. J Oncol Pract. 2012;8(5):e114-24.

29 Abolfotouh MA, BaniMustafa A, Salam M, Al-Assiri M, Aldebasi B, Bushnak I. Use of smartphone and perception towards the usefulness and practicality of its medical applications among healthcare workers in Saudi Arabia. BMC Health Serv Res. 2019;19(1):826.

30 Pershad Y, Hangge PT, Albadawi H, Oklu R. Social medicine: twitter in healthcare. J Clin Med. 2018;7(6):121.

31 Brown J, Ryan C, Harris A. How doctors view and use social media: a national survey. J Med Internet Res. 2014;16(12):e267.

32 Mishra S. When patients connect with physicians on facebook: physician perspectives on benefits, challenges, and strategies for managing interaction. Health Technol. 2018;9(4): 505-15.

33 Liao Y. Sharing personal health information on social media: balancing self-presentation and privacy. ICWSM. 2019. p. 194-204.

34 Alanzi T, Alfuraikh A. Do health care providers pay attention to sharing hospital patient safety incidents through social media in Saudi Arabia? J Patient Saf. 2022 Jan 1;18(1):e211-6.

35 Denecke K, Bamidis P, Bond C, Gabarron E, Househ M, Lau AYS, et al. Ethical issues of social media usage in healthcare. Yearb Med Inform. 2015;10(1):137-47.

36 Chretien KC, Kind T. Social media and clinical care: ethical, professional, and social implications. Circulation. 2013;127(13):141321.

37 Nittari G, Khuman R, Baldoni S, Pallotta G, Battineni G, Sirignano A, et al. Telemedicine practice: review of the current ethical and legal challenges. Telemed J E Health. 2020; 26(12):1427-37.

38 Van der Velden M, El Emam K. "Not all my friends need to know": a qualitative study of teenage patients, privacy, and social media. $J$ Am Med Inform Assoc. 2013;20(1):16-24. 